\title{
DILEMAS DE PROFESSORES TUTORES INICIANTES NA EDUCAÇÃO A DISTÂNCIA
}

\section{DILEMAS OF BEGINNING TEACHERS AT DISTANCE EDUCATION}

Sirlene Fabris Costa*

Rita Buzzi Rausch*

\begin{abstract}
Resumo: O objetivo geral dessa pesquisa foi compreender que dilemas dos tutores iniciantes se fazem presentes na $\mathrm{EaD}$, em cursos ofertados por uma faculdade privada do estado de Santa Catarina. Autores como Tardif (1997; 2002; 2008), Nóvoa (2009); Pimenta (1999); Schlemmer (2009; 2012), Moran (2011), Belloni (2008), entre outros contribuem na discussão desta nova modalidade de ensinar e aprender. A pesquisa se justifica, pois traz uma reflexão destes dilemas em uma modalidade de educação cada vez mais presente no ensino superior. Os principais dilemas apresentados foram quanto à dificuldade de desenvolver um processo de mediação da aprendizagem dos alunos; a necessidade de conhecer o conteúdo de diversas disciplinas; a não autonomia nos processos de avaliação da aprendizagem dos alunos; a pouca maturidade de alguns alunos; a falta de formação continuada específica e a necessidade de constituir uma identidade profissional docente na EaD. Conclui-se que a pesquisa propiciou uma reavaliação dos dilemas presentes na EaD e identificou a necessidade de avanços no desenvolvimento profissional docente do professor tutor iniciante.
\end{abstract}

Palavras-chave: Professores tutores iniciantes. Educação a distância. Educação superior.

Abstract: The main goal of this research was to understand the dilemmas faced by beginning teachers at Distance Education who work in the courses offered by a private college in the state of Santa Catarina. Authors such as Tardif (1997; 2002; 2008), Nóvoa (2009); Pimenta (1999); Schlemmer (2009; 2012), Moran (2011), Belloni (2008), and others contribute to the discussion of this new teaching and learning modality. The importance of this research lies in the fact that it reflects about the dilemmas in a modality of education increasingly present in higher education. The main dilemmas emphasized are related to the difficulty of developing mediation processes in students learning; the need to know the content of several disciplines; the lack of autonomy to evaluate students' learning; the level of maturity of some students; the lack of specific continuing education, and the need to develop a teaching professional identity at Distance Education. The research provided the reevaluation of the dilemmas of Distance Education, in addition to pointing out the need for improvement in the professional development of beginning teachers.

Keywords: Beginning teachers. Distance education. Higher education.

\footnotetext{
* Mestre em Educação pela FURB. E-mail: <sirlene@sirlenecosta.com.br>.

* Master in Education from FURB. E-mail: <sirlene@sirlenecosta.com.br>.

** Doutora em educação pela UNICAMP. Docente pesquisadora no Programa de Pós-Graduação em Educação da FURB. E-mail: <ritabuzzirausch@gmail.com>.

${ }^{* *}$ Doctor in education from the UNICAMP. Professor at the Post Graduate in Education at the FURB. E-mail: <ritabuzzirausch@gmail.com>.
} 


\section{Introdução}

A proposta desta pesquisa encontra suas bases nas discussões atuais sobre formação docente, que têm permeado muitas pesquisas educacionais. A modalidade de educação a distância vem ganhando cada vez mais espaço no ensino superior, o que tem contribuído com o aumento do número de instituições que estão passando a ofertar cursos na modalidade EaD. Desta maneira, decidimos pesquisar os dilemas de professores tutores iniciantes na educação a distância por meio de estudos bibliográficos e de campo.

Diante disso, esta pesquisa busca respostas para a seguinte indagação: quais são os principais dilemas de professores tutores iniciantes em cursos ofertados por uma faculdade privada do estado de Santa Catarina? No desenvolvimento desta reflexão, o objetivo do estudo foi compreender os principais dilemas dos professores tutores iniciantes na modalidade a distância.

Para a realização do trabalho de campo, buscamos uma faculdade privada de ensino superior de Joinville, na qual a modalidade EaD já é uma realidade há dois anos e contou com envolvimento de professores tutores iniciantes. Quanto à base teórica desta pesquisa, fundamenta-se principalmente nas contribuições de Tardif (1997; 2002), Nóvoa (2009); Pimenta (1999), Moran (2007; 2011), Schlemmer (2006, 2012), Belloni (2008), entre outros, sendo que os últimos três autores desenvolvem estudos sobre a $\mathrm{EaD}$ e apontam diferentes conceitos que, apesar da falta de homogeneidade, permitem uma compreensão mais clara do que é esta modalidade.

O estudo se justifica por trazer à reflexão um tema atual que são os dilemas vividos pelos professores tutores iniciantes, na $\mathrm{EaD}$ na sua prática docente, com toda sua complexidade e diferenças em relação à educação regular.

\section{A educação a distância no ensino superior}

As universidades vêm influenciando e sendo influenciadas pelo ambiente em que estão inseridas no contexto educacional. O advento das tecnologias de informação e comunicação e suas diferentes possibilidades de uso tem potencializado as oportunidades de oferta de programas educacionais a distância. Muitos são as oportunidades e dilemas dos tutores na educação a distância.

Lemos (2002, p. 95) afirma que tecnologia "deve fazer parte da cultura, já que ela é constitutiva do homem.” Refutar a técnica é refutar a humanidade como um todo, é refutar essa humanidade que "é" por uma hipotética que "deveria ser”. Portanto, verificamos, com base nestes autores, que a tecnologia está inserida na educação como um apoio no processo de ensinar e de aprender.

A educação a distância começa a tomar forma e ser mais amplamente divulgada e disseminada a partir dos anos 60 , com a institucionalização de várias ações nos campos da educação, secundária e superior, em vários países do mundo, inclusive no Brasil. Schlemmer (2005, p. 31) define a educação a distância como

utilizar as tecnologias da internet para propiciar um amplo conjunto de soluções que objetivam servir de suporte para que a aprendizagem ocorra.

Para esta autora, a EaD se utiliza das tecnologias da Internet para propiciar um amplo conjunto de soluções que objetivam servir de suporte para que a aprendizagem ocorra.

Vieira Pinto (2011, p. 210) apresenta o conceito de filosofia da técnica como

a arte de fazer surgir sempre algo novo; coloca a importância da técnica como libertadora e a recusa como um mero perigo de nossa espécie, concluindo com isso que sempre é o homem o construtor de seu ambiente e de sua qualidade de vida. 
Para ele, é um erro primordial olhar para as coisas produzidas a partir da técnica simplesmente, "pois a verdadeira finalidade da produção humana consiste na produção das relações sociais, a construção de formas de convivência”. O autor enfatiza que o que domina a essência do homem são as leis da natureza e, por consequência, outro homem.

No Brasil, a Secretaria de Educação a Distância - SEED, criada pelo MEC, define no Decreto 5.622 ${ }^{1}$, de 19.12.2005 (que revoga o Decreto 2.494/98), regulamenta o Art. 80 da Lei 9394/96 (LDB), artigo $1^{\circ}$, educação a distância como:

A Educação a Distância é a modalidade educacional na qual a mediação didático-pedagógica, nos processos de ensino e aprendizagem ocorre com a utilização de meios e tecnologias de informação e comunicação, com estudantes e professores desenvolvendo atividades educativas em lugares ou tempos diversos. (BRASIL, 2005, s/p).

Outra preocupação do MEC é quanto aos docentes dos cursos da EaD. Em um documento intitulado Referências de Qualidade para a EaD, publicado em 2007, o MEC (BRASIL, 2007) revela que: em primeiro lugar, é

enganoso considerar que programas a distância minimizam o trabalho e a mediação do professor. Muito pelo contrário, nos cursos superiores a distância, os professores veem suas funções se expandirem, o que requer que sejam altamente qualificados.

\footnotetext{
${ }^{1}$ O Decreto 5.622, de 19.12.2005 (que revoga o Decreto 2.494/98), que regulamenta o Art. 80 da Lei 9394/96 (LDB) Educação a Distância como: A Educação a Distância é a modalidade educacional na qual a mediação didáticopedagógica nos processos de ensino e aprendizagem ocorre com a utilização de meios e tecnologias de informação e comunicação, com estudantes e professores desenvolvendo atividades educativas em lugares ou tempos diversos (BRASIL, 2005).
}

Desenvolver uma reflexão sobre o papel do professor na modalidade a distância, investigando-se quais são os dilemas vividos, é fundamental para o sucesso da aprendizagem do aluno e a própria EaD como um todo.

A educação a distância é um tema relativamente novo quando pensamos na educação superior vigente no país. Por esta razão, torna-se essencial à universidade o desenvolvimento da pesquisa, também em relação à $\mathrm{EaD}$, para prover novas ideias e descobertas.

De acordo com dados do Censo de Educação Superior de 2010, a EaD, praticamente inexistente há dez anos, já responde pelo percentual de $14,6 \%$ do total das matrículas da graduação. Atualmente, são 148 instituições credenciadas no Ministério da Educação e oferecem 1752 cursos de graduação e pós-graduação na modalidade a distância, um total de 1.075.272 alunos matriculados. O decreto no 5622 (19/12/ 2005) que regulamenta o Art. 80 da Lei de Diretrizes e Bases (LDB) - 9.394/96 que reconheceu a EaD, evidencia um crescimento significativo de $65 \%$ ao ano, na oferta de formação nessa modalidade. A EaD em cursos de graduação tem mantido um crescimento em torno de $50 \%$ ao ano. No período de 2000 a 2008, a educação a distância no país deu um salto de 1.682 para 760.599 alunos que estudam por meio dessa modalidade de ensino.

De acordo com os números apresentados, a expansão da EaD no Brasil nos induz a uma reflexão sobre a qualidade do ensino superior, assim como a questão política de acesso e a necessidade de formação dos profissionais de educação, direcionados para essa modalidade.

\section{Professores tutores iniciantes}

A tutoria presencial, segundo Mill (2007), “é composta pelo grupo de 
educadores que acompanha os alunos, presencialmente, com encontros frequentes ou esporádicos”. O professor tutor presencial está junto aos alunos, face a face, promovendo interação com os conteúdos, com o professor e com outros alunos, utilizando-se também, em alguns momentos, de tecnologias. Esse contato ocorre em virtude da utilização da mídia: TV, vídeo, web, impressa ou ainda combinando algumas delas. Nesses encontros, o professor tutor é quem encaminha o processo de contato do aluno com o conteúdo, orientando, acompanhando e provocando sua aprendizagem. A tutoria presencial permite atendimento individualizado e em grupo, facilita a organização de grupos de trabalho cooperativo e colaborativo e é essencial em aulas práticas.

No contexto da EaD, o tutor representa o papel de um mediador, orientador na construção do conhecimento, da informação. Há uma relação de compartilhamento, e não de defesa, proteção. O tutor é um professor que atua nas situações programadas de ensino e aprendizagem, além de promover ou desenvolver orientação assistida nos processos de educação a distância. Os tutores iniciantes e seus dilemas são objetos de estudo desta investigação.

Autores como Huberman (1992) e Tardif (2007) estabelecem o início da carreira como uma fase mesclada de incertezas e dilemas, frente à submissão do professor às normas do trabalho e sua relação com a prática docente adquiridos na formação. Ele explica esse momento na vida do professor, como o período da sobrevivência ou choque do real-que pode, em contrapartida, tornar-se um rico período de descobertas. Nesta fase surge um comprometimento definitivo com a identidade profissional, de modo que somente a partir desse momento é possível ter segurança na carreira escolhida para diversificar ou mesmo para questionar-se.
É importante notar que a socialização do professor contribui favoravelmente nesse início de carreira, pois é através da troca entre os professores, da cooperação com os colegas e mesmo do apoio da instituição; que o professor alcança a estabilidade, a segurança sobre o que pretende fazer e sobre como o fará, sentindo-se parte do grupo.

Assim, devido à grande diversidade de obstáculos que o professor encontra no decorrer de sua atuação, não há como pensar que sua formação pode manter-se estagnada.

A continuidade do processo de formação deve estar presente no decorrer de sua carreira, não apenas na busca do conhecimento teórico, mas também no compartilhamento de experiências e de informações que vão surgindo no decorrer de cada trajetória.

A realidade leva o professor iniciante a um período de preocupação constante com seu modo de atuar, de enfrentar e agir diante das dificuldades dos alunos, o que, por vezes, o leva a imitar os demais em prol da chamada "sobrevivência”. Tornar-se professor, assim como tornar-se tutor, é um processo de profissionalização que passa por algumas etapas, sendo muito importantes nesta trajetória as primeiras experiências profissionais.

Huberman intentou "fases" que descrevessem percurso de indivíduos de várias ou uma profissão. Apresenta assim um conjunto com sete diferentes fases, estágios: Entrada na Carreira; Fase de Estabilização; Fase de Diversificação; Pôr-se em questão; Serenidade e Distanciamento Afetivo; Conservantismo e Lamentações e, por último, Desinvestimento.

O Quadro 1 demonstra as características de cada fase do ciclo de vida do professor, conforme o entendimento de Huberman. 
Quadro 1 - Fases do ciclo de vida do professor

\begin{tabular}{|l|l|}
\hline Fase & Características \\
\hline Primeiros 3 anos & Entrada e tateamento \\
\hline De 4 a 6 anos & Estabilização, consolidação de um repertório pedagógico. \\
\hline Entre 7 e 25 anos & Ocorre a diversificação, ativismo ou questionamento. \\
\hline Entre 25 e 35 anos & Ocorre o desinvestimento (sereno ou amargo) \\
\hline
\end{tabular}

Fonte: Adaptado de Huberman (1992, p. 6)

Portanto, de acordo com esse quadro, os primeiros três anos da profissão dos docentes correspondem ao ingresso na carreira, com a fase que Huberman chama de "tateamento”, ou seja, a descoberta das peculiaridades da profissão e a adaptação às diversas realidades e imprevistos da carreira.

Na segunda fase, quando já tem de quatro a seis anos de profissão, o professor alcança um nível de estabilização, consolida-se na carreira e desenvolve um repertório pedagógico; na sequência, entre sete e vinte e cinco anos de profissão, ele busca diversificar seu repertório pedagógico, questiona os conteúdos e torna-se ativista; por fim, na última fase, os profissionais não investem mais na carreira, e isto pode ocorrer de forma serena ou amarga, dependendo da pessoa e da experiência que teve em sua trajetória docente. A fase da "sobrevivência" é o resultado do primeiro confronto com a complexidade da situação profissional, o que o autor chama de "choque do real”. Ocorre um confronto inicial com a enorme complexidade do trabalho atribuído à camada docente, realidade com que a maior parte dos professores experientes lidam. A fase da “descoberta” traduz o entusiasmo inicial do novo professor em ter uma turma e um programa pelos quais é responsável, a sensação de importância por fazer parte de um corpo docente. Para muitos professores, esse é um aspecto vivenciado positivamente, que os ajuda na superação dos problemas rela- cionados com a sobrevivência. A etapa da estabilização transcorre entre o quarto e o sexto anos de carreira e resulta de uma escolha pessoal e subjetiva de escolher a docência como carreira, que é confirmada por um ato administrativo que sela um compromisso entre o indivíduo e a instituição, culminando num comprometimento definitivo no seio da classe docente. O professor faz parte de um corpo profissional, tem independência e autonomia, afirma-se perante os colegas e as autoridades. Essa fase altamente afirmativa, em que o indivíduo se reconhece como professor perante os olhos alheios e aos seus próprios, estende-se por um período de oito a dez anos. Para Huberman, o ciclo de vida profissional incide sobre o modo evolutivo e o percurso profissional dos docentes.

Marchesi (2008) define a trajetória profissional docente da seguinte forma: após a fase inicial, marcada por sentimentos de sobrevivência e de descobertas (de um a três anos), vem a estabilização (de quatro a seis anos). Terminada esta fase, muitos profissionais se encontram em um dilema de vida: alguns se encaminham para a experimentação e ativismo, outros reavaliam sua profissão, entram em conflito com seus ideais de vida e valores profissionais e ficam com muitas dúvidas.

Na próxima fase, entre sete e 25 anos de trabalho, os profissionais ativistas encontram serenidade nas relações e certo distanciamento dos problemas da profissão. Já os 
que passaram, na fase anterior, pela reavaliação e por dúvidas, enfrentam essa fase com conservadorismo. $\mathrm{Na}$ última fase da carreira, de 25 a 35 anos de profissão, os docentes que na fase anterior desenvolveram distanciamento enfrentam esse final de falta de comprometimento com serenidade. Já os que passaram na fase anterior pelo conservadorismo enfrentam o final de carreira com amargura. O ciclo de vida profissional tem um impacto importante nesta pesquisa, pois será discutido sob a perspectiva do professor iniciante,um período que associa o início da carreira à falta de vínculo com o cotidiano da escola.

\section{Reflexões sobre o método, campo e sujeitos da pesquisa}

Nesta pesquisa, privilegiou-se a abordagem qualitativa como perspectiva metodológica e analisam-se os depoimentos de professores tutores iniciantes, pois entendemos que são as experiências e as condições de vida que fornecem ao pesquisador elementos para a elaboração de conceitos e análise das ações dos sujeitos e da instituição da qual fazem parte.

O método qualitativo possui premissas pela obtenção de dados descritivos por meio do contato direto e interativo do pesquisador com o objeto de estudo. Bogdan e Biklen(1999) apresentam certas características importantes para este tipo de pesquisa: tem o ambiente natural como fonte direta dos dados e o pesquisador como instrumento chave. $\mathrm{O}$ pesquisador qualitativo cria deliberadamente espaços para o aparecimento de conteúdos e aspectos não previstos inicialmente (BOGDAN; BIKLEN, 1999).

Foram selecionadas para a aplicação da pesquisa de campo dois campi da mesma instituição em cidades distintas do estado de
Santa Catarina; ambos possuem uma trajetória curta de dois anos apenas na oferta de cursos de graduação na modalidade a distância. A pesquisa foi realizada nos cursos de graduação da modalidade a distância: Serviço Social, Administração de Empresas ênfase em Administração Industrial, Marketing, Ciências Contábeis e Pedagogia.

Os principais critérios para a escolha dos professores participantes da pesquisa foram que: a) atuassem como professores tutores da educação a distância; b) atuassem como professores da educação a distância há não mais do que três anos; c) fossem professores tutores presenciais; d) concordassem em fazer parte da pesquisa; foram selecionados um total de nove professores tutores iniciantes os mesmos foram classificados com a letra $\mathrm{P}$, ordenados consecutivamente, de acordo com as entrevistas realizadas (P1, P2, P3,...).

No Quadro 2,constam as características e o perfil dos professores tutores iniciantes entrevistados. 
Quadro 2 - características dos sujeitos da pesquisa

\begin{tabular}{|c|c|c|c|c|c|c|c|}
\hline Professores & Gênero & Idade & Graduação & $\begin{array}{c}\text { Pós-graduação } \\
\text { (especialização) }\end{array}$ & $\begin{array}{c}\text { Tempo de } \\
\text { docência } \\
\text { presencial }\end{array}$ & $\begin{array}{c}\text { Tempo de } \\
\text { docência } \\
\text { EAD }\end{array}$ & $\begin{array}{c}\text { Curso de } \\
\text { atuação EAD }\end{array}$ \\
\hline P 1 & Feminino & 29 anos & Ciências Contábeis & Administração & 8 meses & 8 meses & $\begin{array}{c}\text { Ciências } \\
\text { Contábeis }\end{array}$ \\
\hline P 2 & Masculino & 40 anos & Administração E. & $\begin{array}{c}\text { Gestão Estratégica } \\
\text { Empresarial }\end{array}$ & Não atuou & 6 meses & $\begin{array}{c}\text { Administração } \\
\text { de Empresas }\end{array}$ \\
\hline P 3 & Feminino & 35 anos & Serviço Social & Psicologia & 1 ano & 1 ano & Serviço Social \\
\hline P 4 & Masculino & 42 anos & Administração E. & $\begin{array}{c}\text { Administração } \\
\text { Industrial }\end{array}$ & 1 mês & 2 anos & $\begin{array}{c}\text { Administração } \\
\text { de Empresas }\end{array}$ \\
\hline P 5 & Feminino & 43 anos & Pedagogia & Pedagogia & 17 anos & 1 ano & Pedagogia \\
\hline P6 & Masculino & 35 anos & $\begin{array}{c}\text { Administração de } \\
\text { Empresas }\end{array}$ & $\begin{array}{c}\text { Logística (2009) e } \\
\text { MBA Gestão de } \\
\text { Pessoas (andamento) }\end{array}$ & Não atuou & $\begin{array}{c}7 \text { meses } \\
\text { Administração } \\
\text { de Empresas }\end{array}$ \\
\hline P 7 & Masculino & 33 anos & Administração E. & Logística & 1 ano & 1 ano & $\begin{array}{c}\text { Administração } \\
\text { de Empresas }\end{array}$ \\
\hline P 8 & Feminino & 31 anos & Pedagogia & $\begin{array}{c}\text { Psicopedagogia e } \\
\text { Mestrado incompleto }\end{array}$ & 15 anos & 3 anos & Pedagogia \\
\hline
\end{tabular}

Fonte: Instrumento de recolha dos dados - entrevista

No Quadro 2, quanto ao gênero dos professores tutores iniciantes, temos quatro femininos e cinco masculinos; quatro professores tutores estão na faixa etária entre 40 a 45 anos, quatro na faixa etária de 31 a 35 anos e um professor tutor com 29 anos.A profissão atual dos professores tutores iniciantes, todos são professores tutores e trabalham em outras atividades, tais como orientação pedagógica, coordenação de projetos especiais, supervisão de logística, professor do curso superior presencial, consultor de empresas e os outros quatro atuam apenas na tutoria.

Com relação à escolaridade, todos os professores tutores possuem formação em nível superior, com especialização em nível de pós-graduação. Destes, dois possuem uma especialização já concluída e outra em andamento. Somente um iniciou o Mestrado e “desistiu". Quanto ao tempo de docência na EaD, observou-se: um professor atua por três anos na atividade, outros oito, atuam de seis meses a dois anos como professores tutores. Todos os entrevistados indicam a prática de sala de aula com os alunos como o componente mais forte na aprendizagem docente. Para cinco deles, essa prática pode ser configurada como um processo de ensaio e erro, em que tanto um quanto outro podem ocorrer. Esse fato, pelos relatos apresentados, confirma insegurança e receio do "novo", da EaD.

Retomamos, a seguir, a questão da evolução e da importância do ciclo de vida profissional do docente descrito por Huberman (1992), numa tentativa de proporcionar conhecimentos sobre as etapas particulares da vida profissional.

O início da docência, a iniciação na carreira e a formação contínua caracterizam-se pela fase inicial de inserção na docência, basicamente, pela passagem de estudante a professor, começada já durante o processo de formação inicial. 
Quanto à idade cronológica dos professores tutores pesquisados, a média de idade foi de 37 anos. Huberman (1992) enfatiza que é dos 28 aos 33 anos a fase em que assumem novas responsabilidades. $\mathrm{O}$ peso da formação é já distante, valorizando-se o saber vindo da experiência. Em termos profissionais, já possui certa segurança, o que facilita sua relação com o trabalho. Neste mesmo período de idade, reforça que os professores vivem a fase da estabilização - ao mesmo tempo em que há uma tomada de responsabilidades, ocorre um comprometimento.

Dos professores tutores pesquisados, cinco consideram que têm experiência na educação a distância e quatro, consideram não ter esta experiência. Aqui cabe ressaltar que todos para esta pesquisa foram considerados professores tutores iniciantes, com até três anos de experiência. Quando questionados sobre se foram capacitados para atuarem nessa função na educação a distância, oito disseram que não foram capacitados, apenas um confirmou que participou de uma capacitação para atuar como professor tutor.

No quesito formação para atuar como professor tutor, os nove professores estão atualmente participando de uma especialização em nível de pós-graduação sobre Gestão e Metodologia da EaD, oferecida pela própria instituição. Estes relatam a dificuldade em conciliar as tarefas exigidas pelo curso com as outras atividades diárias.

O instrumento de coleta de dados selecionados foi a entrevista semiestruturada.

Considerando este tipo de análise e as afirmações dos professores tutores iniciantes, foram definidas a posteriori as seguintes categorias de análise: Dimensão didático-pedagógica da EaD; Processo de avaliação da aprendizagem na educação a distância; Perfil profissiográfico do aluno da EaD; Identidade profissional docente da EaD.
A técnica de análise utilizada foi a de conteúdo, que conforme Bauer \& Gaskell (2008), não deve ser julgada como uma "leitura verdadeira” do texto, porém, deve ser avaliada conforme sua fundamentação nos materiais pesquisados e em sua congruência, com a teoria do pesquisador à luz do objetivo de pesquisa.

\section{Dilemas de professores tutores iniciantes na educação a distância}

A educação a distância tem trazido novos desafios à formação profissional, especialmente à formação de professores, que requer uma melhor formação para vivenciar a dinâmica social em relação às mudanças do saber na sociedade atual.

Zabalza (1994, p. 74) define dois aspectos do dilema;

um deles é que são construtos descritivos e são próximos da realidade: referem-se a atuações concretas relativas a situações problemáticas no decorrer da aula; outro se refere a romper com a ideia de linearidade da conexão pensamento-ação”. Os trabalhos de Lampert. (apud ZABALZA, 1994, p. 74).

enfatizam que os "dilemas práticos no ensino são inevitáveis e os dilemas constituem o coração do agir profissional dos professores.” Para Lalande (1999), dilema é um "sistema de duas posições contraditórias, entre as quais se é colocado na obrigação de escolher” (p.260). Nesta pesquisa, a partir da interação da pesquisadora com os professores tutores presenciais dos cursos, foi emergindo uma série de dilemas que eles vivenciam na sua prática, bem como o compartilhamento que fazem de suas experiências e reflexões sobre tais impasses.

Os dilemas socializados pelos professores tutores nas entrevistas (sua 
identidade profissional na modalidade EaD, o perfil do aluno nesta modalidade, o sentimento de insegurança diante da necessidade de conhecer o conteúdo de todas as disciplinas do curso) serviram de objeto de reflexão e de pesquisa. A partir dessas interações e da colaboração entre eles, percebe-se a importância do grupo em reconhecer suas formas de enfrentamento e como lidar com estes dilemas. Segundo esses professores, surgiram vários "problemas" considerados por eles como geradores de dilemas, sendo necessário categorizá-los para entendê-los melhor. Assim, foram identificadas quatro subcategorias: 1. Dimensão didáticopedagógica da EaD; 2. Processo de avaliação da aprendizagem na educação a distância; 3 . Perfil profissiográfico do aluno da EaD; 4. Identidade profissional docente da EaD.

\section{Dimensão didático-pedagógica da EaD}

Na análise desta dimensão, destaca-se a necessidade de compreender, acima de tudo, que as dinâmicas formativas precisam contemplar o trabalho colaborativo, de modo que seus sujeitos possam contribuir com o processo de produção coletiva do grupo, socializando seus dilemas e buscando, conjuntamente, seu enfrentamento. Um dos dilemas dos professores tutores relatados na pesquisa diz respeito à inter-relação professor tutor/ aluno na educação a distância.

Para Tardif,

o problema principal do trabalho docente consiste em interagir com alunos que são todos diferentes uns dos outros e, ao mesmo tempo, em atingir objetivos próprios a uma organização de massa baseada em padrões gerais. (TARDIF, 2002, p.145).

Os professores P7 e P4 chamam a atenção para a linguagem corporal dos alu- nos ("levantam o dedo") no processo de aprendizagem presencial, inexequível na EaD. Isso evidencia a dificuldade de comunicação com o professor tutor, o que leva os alunos à frustração:

Nas aulas a distância têm alunos que não consegue expressar para mim suas dúvidas, e nas perguntas não responde na aula, o alunofica frustrado, perguntei e não respondeu. (P7).

Nas falas dos professores P7 e P4, percebe-se que ambos sentem a falta da interação entre professor e aluno. Para que este relacionamento ocorra e se fortaleça, é importante, conforme comenta Tardif, envolver relações de sofrimento e alegria, êxitos e fracassos, que devem ser socializados. Um dos professores tutores (P2) faz referência à dificuldade que enfrenta em relação ao curso ser on-line e demonstra preocupação com o conteúdo a ser ministrado como prioridade, pois o contato com os alunos demanda tempo para ser estabelecido: "Totalmente on-line para mim não dá. Tenho que me preocupar com conteúdo, tecnologia não é tudo, não existe isso". (P2). Percebe-se, portanto, uma preocupação não só em função da ausência física, mas também em relação ao conteúdo programático.

A valorização pessoal e profissional do professor se dá por ter domínio do conteúdo, e assim, corresponder e atender seus alunos. Com base nos achados desta pesquisa, podemos inferir que há “distanciamento” também, do tutor para com sua profissão (tutoria), em decorrência de serem iniciantes e atuarem com novas perspectivas. Há, de fato, uma preocupação desses professores tutores com o conteúdo da disciplina a ser ensinado, o que pode ser evidenciado nos seguintes depoimentos:

Ter paciência para com o sistema (webaula). (P3). 
Ter uma abordagem segura do assunto, a forma de expressão do professor (postura). (P1).

Nota-se que estas referências valorizam o saber disciplinar em detrimento do saber técnico, que é um dos saberes dos professores tutores. Tardif (2000) ainda enfatiza a importância de o professor conhecer a disciplina que leciona,dominar seu conteúdo, pois os professores são os principais mediadores da cultura e dos saberes escolares.

Um dos dilemas importantes dos professores tutores é a mediação. Neste processo, a atividade de construção do conhecimento realiza-se pela mediação. Vygostky (2001, p.26) ressalta que, "em termos genéricos, trata-se de um processo de intervenção de um elemento intermediário quando a relação deixa de ser direta e passa a ser mediada por esse elemento.” Para ele, nossa relação com o mundo acontece a partir das relações que estabelecemos com os sistemas simbólicos que nos rodeiam.

Para Vygostsky, o desenvolvimento mental humano não é dado a priori, não é imutável, não é passivo, nem tampouco independente do desenvolvimento histórico e das formas sociais da vida humana. A mediação está presente em toda atividade humana: são os instrumentos técnicos e sistemas de signos, sinais, construídos historicamente, que fazem a mediação dos seres humanos entre si e com o mundo.Portanto, podemos concluir que quando imaginamos uma sala de aula em um processo interativo; estamos acreditando que todos terão possibilidade de falar, levantar suas hipótese e expor suas ideias e assim, chegar a conclusões que ajudem o aluno a se perceber como parte de um processo dinâmico de construção.

Considerando a contribuição do autor, percebemos que as afirmações dos professores apontam que a presença física de do- centes e estudantes em uma sala de aula não nos dá nenhuma garantia de aprendizagem e que o trabalho em equipe, as reuniões, os contatos entre as pessoas e a interação aluno-professor é que são fundamentais.

Conforme afirma P3, "No presencial, me sinto mais útil, preciso interagir com as pessoas, com meus alunos”. Assim, há uma mudança na estrutura das aulas e cada vez mais o professor tutor necessita lidar com 'consciência coletiva' nas diferenças individuais. (P3).

Outro dilema mencionado é o relacionamento com os colegas, que compartilham os mesmos medos, ansiedades, receios pelo "novo" e buscam trocar entre si "saberes disciplinares" e conhecimento de novas disciplinas que ainda não dominam:

No primeiro semestre, deixei o "barco andando”, depois em específicas como matemática, minha base e experiência com númerosme ajudou bastante, mas procuro conversar com meus colegas, outros professores. (P7).

Segundo essa resposta, o professor P7 relata haver colaboração entre colegas. Nóvoa enfatiza que isso retrata uma formação continuada construtiva:

Esse modelo ocorre em uma relação em que formadores e formandos são colaboradores predispostos aos saberes produzido em ação. O contexto é de cooperação em que todos são corresponsáveis pela resolução dos problemas práticos. (NÓVOA, 1992, p. 27).

Pode-se transportar este conceito para os professores tutores. Segundo eles, o fato de serem responsáveis por todas as disciplinas do curso em que atuam exige um suporte pedagógico. Este suporte ocorre entre seus 
colegas, também professores tutores, num processo de colaboração para o cumprimento de tarefas que lhe são confiadas, conforme relata P2:

Melhorar a questão da linguagem (oratória), ter relacionamento com outros professores, ter uma postura bem mais formal. (P2).

Esta resposta reforça a citação de Tardif sobre a cooperação do trabalho enquanto ofício docente. Por outro lado, interagir com o aluno na educação a distância é fazer parte de um mesmo "palco":

Para os professores tutores entrevistados, conversar, trocar conteúdos, conhecimento e "pedir ajuda" para os colegas é prática corrente neste início de carreira docente na EaD.

Este conceito do que seja "colaborativo" parece ser relevante para o professor tutor P7, quando destacou:

No presencial, o professor está aqui, tem o retorno imediato da reação dos alunos e o outro não tem. $\mathrm{O}$ trabalho em equipe no presencial consegue trabalhar isso.

Na atualidade, o contexto da educação precisa "ter grande atenção à diferença (às diferenças)". Para o autor, o diálogo é a referência da humanidade. Porém, ressalta outras características importantes como a partilha dos saberes e as práticas do trabalho, o coletivo docente, e a procura coletiva das melhores formas de agir. Esta pesquisa propicia uma reflexão, baseada nos depoimentos dos entrevistados, sobre a importância da coletividade entre os professores tutores (colegas de profissão) e com seus alunos.

\section{Processo de avaliação da aprendizagem na educação a distância}

A EaD contempla um modelo de ensino que combina aulas na modalidade presencial e na modalidade a distância, utilizando tecnologias de informação, comunicação e uma variedade de recursos multimídia. É preciso refletir sobre o que avaliar, considerando que tal modalidade dispõe de novos ambientes de aprendizagem que são constituídos, independentemente, da relação professor/aluno observada nas escolas presenciais. O professor avalia não só o aluno, mas também os materiais, os sistemas de suporte administrativo e tecnológico (monitoria e suporte técnico), a ferramenta (sistema tecnológico de gestão/LMS), a logística do sistema e a si mesmo.

No sistema de avaliação na EaD, o aluno deve atingir uma média de $70 \%$ de aproveitamento ao final do curso. Para atingir uma média igual ou superior a $70 \%$, ele será avaliado nas atividades.O professor tutor presencial iniciante avalia o aluno nos fóruns de discussão, nas respostas pelo sistema e na elaboração dos desafios de aprendizagem, que são casos práticos que os alunos devem analisar focando na teoria e prática discutidas em sala de aula. No ambiente virtual, também é possível que o aluno coloque em prática seu aprendizado em sala de aula, por meio da "problematização" e da resolução de problemas. Isso é possível com o uso de uma ferramenta metodológica arrojada, o Desafio de Aprendizagem (DA), sempre com apoio do professor tutor presencial.

Um dos dilemas apontados pelos tutores foi a existência da preocupação quanto à avaliação realizada nesta modalidade de ensino. Um dos entrevistados destaca: “Na $\mathrm{EaD}$ eu não vejo isso, como eu vou avaliar se eles 
estão aprendendo ou não? Na EaD, é complicado” (P5). Com essa resposta, o professor demonstra que vive sentimentos de "insegurança” no exercício de sua profissão, no exercício de tutoria e, especialmente, no processo de avaliação do aluno.

Já o professor tutor presencial P3 referiu-se à metodologia de avaliação na modalidade a distância declarando que se sente incapaz de avaliar seus alunos: "O aluno no EaD faz uma prova com consulta e tira dois, três, quatro, além disso, tira nota baixa” (P3). Acontece que o fato de realizar a prova com consulta não garante uma boa nota, tampouco a aprendizagem deste aluno. Pode-se concluir, portanto, que apesar dos professores fazerem uso do apoio das tecnologias e de novas abordagens para ensinar, ainda assim, a maneira tradicional de avaliar é um meio que repercute sobre os resultados no final da avaliação, a nota.

A dificuldade de implementar a avaliação formativa em cursos de educação a distância é discutida por Belloni (1999. p, 89). O tempo que exige dos docentes pode ser diminuído, buscando-se o suporte das tecnologias, tão presentes nos processos de educação a distância e muito pouco utilizados em benefício da avaliação. Além disso, educando a distância, o professor não está sozinho, ele trabalha com uma equipe, tornando-se um professor coletivo.

Hoffmann (2000, p. 42) destaca que a avaliação desempenha um papel significativo para o modelo social liberal-conservador, ou seja, o papel disciplinador. Os “dados relevantes" que devem ser considerados para o julgamento de valor, tornam-se "irrelevantes”, sendo que o padrão de exigência fica ao livre arbítrio do docente. Esta prática torna a avaliação um instrumento disciplinador de condutas sociais, utilizada como critério para a aprovação dos alunos, buscando con- trolar e disciplinar, retirando destes a espontaneidade, a criticidade e criatividade, transformando-os em "cordeiros” de um sistema autoritário e antipedagógico.

Um dos professores destacou que uma realidade da cultura brasileira no processo de avaliação é a autonomia dos alunos e dos professores tutores neste processo:

No Brasil eu espero sejam autônomos. Tenho três aulas por dia, e na a distância não tem como fazer uma atividade, como fazer uma avaliação. (P7).

O professor tutor comenta a falta de “controle”, retirando destes professores a espontaneidade do processo de avaliação dos alunos. Cabe, então, refletir sobre as exigências dos cursos da modalidade a distância em relação às notas e à cobrança, nas diferentes etapas da avaliação do aluno.

Outro dilema vivenciado por um dos professores tutores refere-se à falta de autonomia no processo de avaliação: “Aplico a prova, tem gabarito pronto. Eu não tenho autonomia e as provas ficam na faculdade” (P2). Afirmam que no sistema de avaliação atual desta modalidade de ensino, o tutor presencial não se tem acesso à média final pelo sistema, visto que a nota do Desafio de Aprendizagem é postada diretamente pelo tutor a distância, ao final de cada módulo. Para estes professores tutores, o processo avaliativo apresenta-se segmentado e eles questionam esta descontinuidade, pois os diversos professores avaliam o aluno com olhares distintos.

Para entender melhor o processo avaliativo que os professores tutores relatam, é importante analisar os tipos de avaliação existentes na modalidade presencial e verificar as que podem ser estendidas para a modalidade a distância, como o trabalho didático, a prova escrita e a participação nas aulas. 
Segundo Hoffman (2000, p.75), “as diferentes modalidades de avaliação nos meios escolares podem ser: formativa, classificatória, diagnóstica, emancipatória e mediadora”. Com essas modalidades, é possível refletir sobre o processo de avaliação na EaD onde, conforme os depoimentos, evidencia-se a necessidade de estudar e desenvolver metodologias a serem empregadas na avaliação a distância, possibilitando avaliações mais dinâmicas e interativas. Assim, a avaliação na EaD deve empregar diversos meios, estar à disposição do aluno para orientá-lo e apoiá-lo e, certamente, não deve apenas mensurar de forma quantitativa o conteúdo, nem tão pouco refletir apenas um momento pontual.

A aprendizagem significativa é reflexiva, construtiva e autorregulada (as pessoas são construtoras de seus próprios conhecimentos). A presença ou ausência de determinada informação não é fator primordial na avaliação, mas sim, como o estudante se organiza, estrutura e utiliza a informação para resolver problemas mais complexos.

A implementação de salas de chat, de listas de discussão e correio eletrônico pode proporcionar subsídios para o processo de avaliação via web, cujos objetivos devem incluir, identificar os pontos fortes e fracos, ajudar o aprendiz a aprender, auxiliá-lo nos estilos de aprendizagem e preferências.

No contexto citado, a avaliação pode ser considerada sempre um processo de comunicação. Na educação a distância, o professor tutor avaliador envia uma mensagem aos alunos emitindo conceitos, como mensagem codificada, que o aluno decodifica da sua maneira. Para que a avaliação se torne formativa, no entanto, a informação deverá ser organizada de forma acessível e fazer sentido aos alunos, tornando-se uma informação útil que "alimente” o diálogo entre os envolvidos no processo.
As falas dos professores tutores evidenciaram que o processo de avaliação não tem autonomia, o que revela uma interferência na confiança deste processo, um distanciamento na relação professor-aluno neste quesito. Demonstram uma sensação de "impotência" diante do processo de desenvolvimento dos alunos. Alegam que não podem avaliá-los devido à "burocracia” do sistema tecnológico, que impõe um “distanciamento" do professor tutor e de seus alunos. Outro ponto importante mencionado é a metodologia das provas, ou seja, as provas são realizadas com consulta do material teórico. Este fato preocupa os professores P3 e $\mathrm{P} 2$, que se ressentem da falta de autonomia e questionam a eficácia do processo avaliativo na EaD.

A jornada de trabalho do professor, segundo alegam os professores tutores iniciantes, não se resume apenas na organização e planejamento das aulas, mas a todas as outras atividades que exercem além da docência. Dos professores tutores entrevistados, dois deles se dedicam exclusivamente à docência, os outros seis trabalham em empresas, indústrias, em consultorias, fazendo uma dupla jornada de trabalho. Segundo depõem, a falta de tempo é um dos fatores que provocam tensões e dilemas, pois provoca neles um sentimento de impotência para atender às necessidades dos alunos. "Que qualidade de ensino terei para ensinar os alunos?” Esta preocupação ficou definida na fala de um dos professores tutores presencial:

Tenho a Pedagogia, busco planejamento, a organização em sala de aula, primo muito pela formação do professor, sempre me questiono: que tipo de profissional vou formar? ( P7).

Por outro lado, há uma preocupação sobre que tipo de profissional formarão para o trabalho e para a vida, pois, como 
professor tutor, falta-lhe tempo para este ofício podendo comprometer a qualidade do seu trabalho docente. Um dos professores tutores (P8) chegou mesmo a questionar sua permanência na educação a distância:

Não sei se vou continuar na EaD ou ir para o presencial. Devo ficar mais uns dois ou três anos na EaD para depois passar para o presencial. (P8).

A docência é um trabalho flexível, porém esses dilemas também traduzem confusão nos papéis de professor. Tardif (2009) faz uma reflexão que

o professor precisa, então, fazer malabarismos com uma multidão de papéis, o que necessariamente causa contradições diante do mandato principal: ensinar e fazer aprender.

Podemos confirmar pelas afirmações dos professores tutores e também pelo cenário que hoje temos na profissão em geral quanto condições de trabalho e na carreira docente necessitando ao professor ter vários empregos para manter-se financeiramente e ter alguma qualidade de vida.

\section{Perfil profissiográfico do aluno da EaD}

A EaD trabalha com várias ferramentas que auxiliam na disseminação da informação. O uso do apoio da tecnologia na educação estabelece um novo perfil do aluno que utiliza estas ferramentas. Conforme atesta P3, o ideal é identificar o perfil do aluno, ou seja, verificar se ele tem as habilidades necessárias para a educação presencial ou a distância:

Eu entendo que o aluno não tem esta maturidade, se pensar neste tipo de ensino. Começar a educar lá atrás(sic), ele vai poder fazer esta opção, para qual caminho devem seguir, que rumos irão tomar presencial ou a distância. (P3).

No caso da opção pela EaD, o aluno precisa desenvolver as habilidades de autonomia em pesquisa e busca pelo conhecimento, além da disciplina. Precisam estudar e desenvolver uma disciplina de estudos, tornando a EaD mais trabalhosa. Segundo P5:

o perfil do aluno da EaD é do aluno mais 'vadio', mas ainda deixam tudo para a última hora". "Isto demonstra a cultura do estudante brasileiro, que não tem a cultura do planejamento, da disciplina, do autoconhecimento e, por isso, muitas vezes não se adapta à EaD. (P5)

De acordo com esta citação, o professor necessita desenvolver outros tipos de relação pedagógica, além de promover mudanças de como lidar com o aluno numa sala de educação a distância.

Hoje, o perfil do aluno universitário, segundo relatos dos professores tutores entrevistados, compõe um perfil de pessoas com maior idade e maturidade, são trabalhadores, profissionais iniciando suas carreiras e com foco no futuro; preocupados, principalmente, na formação contínua. Portanto, o perfil do aluno da EaD deve ser pautado pela autonomia nos estudos, a busca pelo conhecimento, o que os professores entrevistados chamam de “correr atrás”. O aluno terá autonomia para exigir do professor novas formas de se tornar mais ativo, com necessidade de transformação.

Outro ponto, destacado pelo participante P6, considera a cultura do aluno brasileiro um aspecto importante:

O aluno na verdade tem uma forma de ver, devemos considerar a cultura brasileira para avaliar. Eu estou indo à escola e espero que o professor me ensine. (P6). 
Esse tipo de atitude denota certo comodismo, manifestado em algumas atitudes observadas: perguntar repetidas vezes para o professor sobre um determinado assunto, "decorar" a matéria, não expandir os conhecimentos sobre determinado tema, estudar apenas o texto dado em sala de aula.

Para Nóvoa (2000), a noção aqui já tão reiterada de “aprender a aprender”, significa que as pessoas devem buscar o conhecimento num processo contínuo de atualização, que leve cada um a adquirir os instrumentos para uma permanente renovação do saber.

Outro dilema está relacionado às expectativas da educação a distância e, por esta razão, motivar os alunos parece ser mais difícil. Os professores tutores P9 e P1 enfatizam isso:

Muitos alunos desistem quando se deparam com o sistema do $\mathrm{EaD}$, eles acham que é fácil e não é e alguns desistem. A $\mathrm{EaD}$ exige muita leitura, autodidata mesmo. (P9).

Em outras palavras, inferimos que os professores querem dizer que o aluno de hoje não possui a cultura da autonomia diante da figura do professor e precisa aprender a aprender. Os professores tutores identificam o dilema da motivação nos cursos a distância, da permanência dos alunos e de seu rendimento efetivo como um desafio que exige do aluno um novo perfil.

O professor tutor $\mathrm{P} 2$ ressalta que esta modalidade a distância é uma tendência e não tem como “fugir disso", e que cabe ao aluno adaptar-se a esta nova identidade. Esse fenômeno provoca tensões entre os professores, inclusive um sentimento de impotência para atender às necessidades dos alunos, que precisam ter um reforço na motivação:

Mas eu vejo o buscar informação no EaD e este sistema é uma tendência, hoje, nas empresas tem reuniões(sic) com presidentes a distancia, trazendo cada um o seu mundo, não tem como fugir muito. (P2).

O professor tutor P3 faz notar que seus dilemas se colocam diante do fato de o aluno estar inserido num “mundo próprio” e dificuldade em fazer parte deste mundo como professor tutor:

Eu tento trazer minha experiência, a prática, e gostaria de estar recebendo muito dos meus alunos, é muito difícil, eles no mundinho deles. (P4).

Na concepção dos professores tutores, conforme seus depoimentos, os alunos podem ter uma consciência inesperada dos seus papéis na educação a distância. Para o professor tutor $\mathrm{P} 5$, existe a crença de que o aluno percebe a docência como um trabalho que tem a função de corresponder ao conceito que ele possui de professor, ou seja, o professor é alguém cuja profissão é fazer aprender. P5 explica isso:"Eu estou indo na escola e espero que o professor me ensine”(P5).

Para que proceda às escolhas, ou seja, defina qual o “melhor caminho”, o professor tutor P9 fala em maturidade, em o aluno estar preparado, “maduro" para este novo caminho que é a educação a distância e o professor representa a "maturidade" como autonomia, o "andar sozinho”, buscar respostas para suas perguntas, sem necessidade do "professor".

Litto e Formiga (2004) enfatizam que a educação a distância “não é para todos”. Segundo ele, o aluno que precisa do professor ao lado dele, cobrando ou elogiando, não é bom para a educação a distância. P3 faz notar que a maioria dos alunos da EaD estão na faixa dos trinta anos de idade, predominância do gênero feminino e são considerados maduros e disciplinados 
As respostas deixam evidente que existe um perfil desejável para estudar na educação a distância.Nem todos os alunos se enquadram. Algumas características foram pontuadas pelo professor $\mathrm{P} 3$, entre elas, "maturidade, disciplina, gostar de buscar informações e [serem] autônomos nos estudos”. Os professores tutores sugerem que estão conscientes da necessidade de adaptação para com este aluno, porém segundo Tardif (2009, p.170), “só os alunos podem dizer se essa adaptação lhes permite aproveitar da melhor maneira o ensino que lhes é oferecido".

Por meio das respostas desta investigação, ficou evidenciado que os professores tutores iniciantes da faculdade investigada ainda não receberam feedbacks dos alunos quanto a sua atuação docente. Esta atuação é envolvida de muitos dilemas, dúvidas, receios e inseguranças sobre se estão conseguindo “dar conta” da tarefa de ensinar e os alunos de aprender na educação a distância.

\section{Identidade profissional docente na EaD}

Para atingir os objetivos propostos, faz-se agora necessário aprofundar a questão da identidade profissional docente. O mundo dos jovens muda mais depressa do que a escola. Este é um sentimento que os professores tutores pesquisados demonstraram em suas falas. Parece haver mais dificuldade para integrar estas mudanças no ofício docente.

Deve sempre estar criando uma dinâmica, ser criativo, isso exige de nós. (P9).

Estar antenado com as questões virtuais, ter conhecimento de TI, relacionamento e na verdade tem que estar de acordo(domínio) com o que precisa para dar aula. (P2).

Os professores tutores presenciais demonstraram, pelas respostas, uma reflexão sobre sua identidade profissional na modalidade a distância e a necessidade do apoio da tecnologia para seu ofício.

Pelos depoimentos dos professores tutores, esta evolução deve continuar. Os professores não podem mais se comportar como simples transmissores de conhecimento estável, vivendo em meio à multiplicação de inovações, à educação digital, às novas técnicas, à velocidade sempre maior colocada em circulação. Tardif (2009, p. 145) comenta que

neste momento de transição, desaparecem os objetos e saberes, certezas e ideias, provocam nos professores o sentimento de estar sendo continuamente ultrapassados.

Segundo declara P2, há uma preocupação com o novo perfil profissional do professor. Já em relação ao aluno da modalidade a distância, $\mathrm{P} 4$ destaca algumas características:

Eu vejo o aluno na EaD, tem pessoas novas e de mais idade, quase se aposentando. A maturidade deste aluno é mais avançada, ele está lá porque ele quer. Identificar quem tem interesse e como tratá-lo, isso é importante. São maduros e adultos.(P4).

Compreender a identidade profissional do professor está diretamente ligado à interpretação social da sua profissão. Assim, considera-se que os movimentos sociais têm intrínseca relação com os projetos educacionais. De acordo com Pimenta, a identidade do professor, é construída a partir dos significados sociais da profissão, da reafirmação das práticas. Podemos afirmar que a identidade profissional desenvolve-se e adapta-se ao contexto social, político e histórico, em que está inserido o professor, enquanto o perfil profissional do professor, muitas vezes confundido com identidade profissional, desenvolve-se durante a sua formação acadêmica, neste caso, a formação docente. 
No que se refere ao "papel” ou identidade profissional dos professores tutores, um deles traduz num depoimento o sentimento de colocar-se no lugar do aluno e reconhecer suas dificuldades como professor tutor:

As dificuldades que o EaD está tendo hoje eu tenho na pele, tais como fazer postagem e outros. Como vou exigir deles se eu também estou tendo dificuldades? (P7).

Há professores tutores que vivenciam esta “adaptação tecnológica” (TARDIF, 2009, p. 216) como uma evolução dos tempos, um momento de mudança, o que também pode ser considerado um dilema. O professor tutor P1 é um dos que responderam a esta afirmativa:

Os métodos que usavam comigo quando eu estava no banco da escola, eles são totalmente diferentes dos aplicados hoje. Se eu for falar que deve escrever no quadro, não aplico mais, tem tecnologias que. São estas diferenças que a tecnologia, as culturas vão mudando. (P1).

Entendese que a construção da identidade docente a partir da instituição da escola dita "moderna” tinha, em sua constituição, elementos que identificavam profissão com vocação, como algo interior que se atualiza na existência do indivíduo. Percebe-se pelas falas dos professores tutores que a origem do ofício de professor tem ainda hoje uma relação com a imagem vocacional, que de alguma maneira ainda se manifesta na ação docente.

Para Tardif (2008, p. 107),

é impossível compreender a questão da identidade dos professores sem inseri-la imediatamente na história dos próprios atores, de suas ações, projetos e desenvolvimento profissional.
O professor tutor pesquisado, $\mathrm{P} 8$, fala da necessidade de confiar na tecnologia:

A confiança na tecnologia mesmo, para falar com propriedade eu preciso ter tranquilidade, para ser professor na educação a distância. (P8).

Na opinião de P8, para sentir-se professor, ele deve ter o domínio da tecnologia e paciência para aprender outros saberes. "Falar com propriedade” envolve sentir-se professor tutor, ou preparar-se para sê-lo. Já o professor P4 enfatiza sua formação enquanto aluno e o papel que exerce, como professor tutor: "Eu venho do ensino presencial, como aluno, e hoje tenho a educação a distância como professor."(P4).

O professor tutor P4 demonstra o desejo de ser professor e de buscar sua identidade e seu conhecimento nos saberes cotidianos, para assim construir sua carreira docente. Ele afirma:

Sempre tive interesse em ser professor, mas sempre tinha um medo como seria. Procurei me preparar, estudar, mas não fui preparado pela instituição. (P4).

A fala de P4 remete a uma identidade em construção, pois, segundo este depoimento, trata-se de sua primeira experiência docente.

Tardif (2001) considera que a formação docente preocupa-se cada vez mais com a formação de uma nova identidade docente, baseada em princípios éticos, investigativos, críticos e reflexivos. Para os professores tutores pesquisados, há uma preocupação na educação a distância de ações investigativas, reflexivas, de novas tendências para sua prática docente. Em suma, a identidade do professor tutor, oscila mais ainda para obter seus novos contornos, à medida que as proposições da EaD implicam em alterações 
na divisão do trabalho entre os docentes do ensino superior, bem como no rompimento entre tempo, espaço e lugar.

Os professores tutores pesquisados trouxeram em seus depoimentos um dilema a respeito destes saberes e de suas necessidades para atuar como professores tutores na educação a distância.

Um dos dilemas apontados pelos professores tutores diz respeito à necessidade de formação específica para atuarem na educação a distância. Eles declaram que, como professores tutores presenciais ou a distância, muitos não foram formados, principalmente no suporte tecnológico para atuarem com o sistema Moodle. A resposta de P6 reproduz este dilema: "No início não tive nenhuma capacitação" (P6).

Para os professores, o dilema se coloca a partir do momento em que não foram preparados para a atividade de professores tutores. Pertencer a uma ocupação, para Tardif (2008, p. 80), significa para os indivíduos que os papéis profissionais que são chamados a desempenhar remetem a normas que devem adotar no tocante a essa ocupação.

Durante as considerações realizadas nesta categoria, ficou evidenciado que os tutores encaram a docência na EaD como um desafio, reconhecem saberes, apontam necessidades de desenvolvimento e mostram-se comprometidos com seu ofício.

Entende-se que estudar a identidade docente é buscar compreender quem somos e como nos tornamos o que somos a partir do mundo em que vivemos. Quanto ao objeto específico deste texto, a identidade docente em tempos de educação a distância, acredita-se que ela tem sido construída num processo de fluidez, flexibilidade, deslocada do sujeito individual e localizada nas fissuras que conectam os mais diversos agentes do processo, pois falamos de diferentes tipos de tutores (presencial, a distância e conteudista) e seus alunos.Verifica-se que este estudo precisaria ter continuidade nas discussões sobre sua compreensão, saberes e dilemas de tutores iniciantes, para desencadear novas propostas, que contemplem a mediação na educação a distância.

\section{Considerações finais}

O presente estudo exige uma reflexão sobre os resultados da pesquisa, de maneira a apresentar considerações finais, enfatizando que eles oportunizam e inspiram novas pesquisas. Finalizar um trabalho como este é desafiador, considerando nossa história e a possibilidade de novos caminhos. Ao buscar responder à questão problema,

Quais os dilemas docentes que se fazem presentes na EaD, entre professores tutores iniciantes em cursos ofertados por uma faculdade privada do estado de Santa Catarina,

queremos pontuar as lições aprendidas durante a pesquisa.

Vários e diversos foram os dilemas citados pelos professores tutores iniciantes e estão relacionados à mediação na aprendizagem dos alunos; ao conhecimento do conteúdo das diversas disciplinas; à autonomia do professor tutor na avaliação da aprendizagem dos alunos; à maturidade dos alunos; à formação específica e processos formativos continuados e sua identidade profissional docente.

Quanto à dimensão didática - pedagógica da $\mathrm{EaD}$, destaca-se a necessidade de compreender, acima de tudo, que as dinâmicas formativas e um dilema mencionado está no relacionamento com os colegas, pois compartilham os mesmos medos, ansieda- 
des, receios pelo novo e buscam estabelecer trocas entre ele. Outro dilema presente são as interações, colaboração entre pares, colegas de profissão, relacionamento com seus colegas tutores; compartilham de diversos sentimentos relacionados a novas situações, novas vivências e um novo papel da docência.

A valorização das relações com alunos e pares, momentos de trocas que se fazem necessários nesta fase inicial da tutoria, propiciando segurança e compreensão efetiva do processo de tutoria. É preciso ter paciência com o sistema de ensino a distância, ou seja, com a tecnologia e o tutor precisa interagir com o aluno, incentivá-lo para esta modalidade que difere da educação na modalidade presencial.

No que se refere ao processo de avaliação da aprendizagem na EaD, um dilema apontado por um dos professores tutores refere-se à falta de autonomia poder atuar com liberdade e autonomia, terá condições de planejar alternativas para o processo de cada aluno. Nos depoimentos dos professores tutores, a falta de tempo é citada como um dos fatores que provocam tensões, dilemas entre os professores tutores, pois eles descrevem um sentimento de impotência para atender às necessidades dos alunos. Ficam evidentes os momentos de incerteza na profissão de tutor iniciante.

O perfil profissiográfico do aluno da $\mathrm{EaD}$, a sua jornada de trabalho é outro dilema, pois a maioria trabalha em outras atividades, até em quatro lugares diferentes, ou seja, não há exclusividade da carreira de professor, o que pode interferir no seu desempenho docente. O aluno da EaD precisa estar preparado para estudar de forma autônoma e precisa desenvolver uma nova postura, diferente daquela adotada na educação tradicional.

Quanto à identidade do professor tutor, busca novos contornos, ela é construída a partir da relevância que cada profissional dá à sua própria atividade docente, por meio de seus valores, atuação no mundo, representações de vida, saberes, sentimentos no seu cotidiano. A questão de como motivar os alunos que têm dificuldades para permanecer nos cursos a distância e corresponder ao que os cursos exigem dos alunos num novo perfil profissional, um novo “papel”. Um dos dilemas diz respeito à necessidade de terem sido formados para atuar na EaD. Compreendemos que os dilemas de professores tutores iniciantes na EaD aparecem como reiterações constantes nas falas dos professores pesquisados. Podemos concluir que:

1. os professores tutores iniciantes embora tenham experiência na educação presencial é como qualquer profissional iniciante,necessita de um acompanhamento, de um "olhar" sobre si, pois se sentem inseguros, com medo. É preciso "cuidar" deste professor, estar "próximo";

2. os professores tutores iniciantes ainda não tem claro a conceituação da $\mathrm{EaD}$, apenas que é um movimento atual e social, ou seja "não tem volta";

3. a tecnologia é uma dificuldade para os professores tutores e sentem-se desafiados nesta modalidade;

4. Na EaD, a presença do “professor” também é importante;

5. um dos dilemas importantes dos professores tutores refere-se à mediação do conhecimento;

6. a postura de um professor passa a ser fundamental a partir do momento em que se estabelece uma comunicação clara, com feedbacks definidos e contínuos;

7. o relacionamento seja com alunos ou pares é fundamental no processo da aprendizagem;

8. a avaliação na EaD necessita ser repensada a partir do momento em que gera insegurança e insatisfação aos professores tutores. 
Diante dessas lições, esta pesquisa permitiu desenvolver atitudes de questionar e analisar os saberes docentes na EaD.

\section{Referências}

ABED. Associação Brasileira de Educação a Distância. CensoEAD.br. Relatório Analítico da Aprendizagem a Distância no Brasil. São Paulo: Pearson Education do Brasil. 2011.

AMORIN, L. Os alunos estão cada vez mais longe. Revista Exame. Disponível em: <http://educarparacrescer.abril.com.br/ gestao-escolar/educacao-distancia-428872. shtml>. Acesso em: 15 maio2011.

BARDIN, L. Análise de conteúdo. Trad. Luís Antero Reto e Augusto Pinheiro.Lisboa: Edições 70, 2002.

BAUER, M. W.; GASKELL, G. Pesquisa qualitativa com texto, imagem e som. Petrópolis: Vozes, 2002.

BOGDAN, R.; BIKLEN, S. Investigação qualitativa em educação: uma introdução à teoria e aos métodos. Porto: Porto Editora, 1999.

BELLONI, M. L. Educação a distância. Campinas: Autores Associados, 1999, p. 13.

BONILLA, H. M. Tecnologias digitais. Disponível em: <www.encontroobservatorio. unb.br/arquivos/artigos/286.pdf>.Acesso em: 12 jan. 2012.

BRASIL. Ministério da Educação. Lei de Diretrizes e Bases da Educação Nacional LDB. 9.394/96, 20 dez. 1996.

Ministério da Educação. Decreto que regulamenta os cursos a distância, MEC, 2002.

Secretaria de Educação Fundamental. Parâmetros Curriculares Nacionais, Brasília, MEC, 2001.
BRASIL. Ministério da Educação. Fundamenta Art. 80 da Lei 9394/96, MEC, 2005.

CASTELLS, M. A. Sociedade em rede. São Paulo: Paz e Terra, 2003.

FORMIGA, M; LITTO, F. M. A terminologia da EAD. In: Educação a distância: o estado da arte. São Paulo: Pearson Education do Brasil, 2009.

FREIRE, P. Pedagogia do oprimido. Rio de Janeiro: Paz e Terra, 2005.

GASKELL, G. Entrevistas individuais e grupais. BAUER, M. W.; GASKELL, G. (Eds.). Pesquisa qualitativa com texto, imagem e som: um manual prático. 7. ed. Petrópolis: Vozes, 2008, p. 64-89.

GAUTHIER, C. et al. Por uma teoria da pedagogia. Ijuí: Unijuí, 1998.

HOFFMAN, J. Avaliação mediadora: uma prática em construção da pré-escola à universidade. 18. ed. Porto Alegre: Mediação, 2000.

HUBERMAN, M. O ciclo de vida profissional dos professores. NÓVOA. A. (Org.).Vida de professores. 2ed. Porto: Porto Editora, 1992, p. 31-63.

LALANDE, A. Vocabulário técnico e crítico de filosofia. 2.ed. São Paulo: Martins fontes, 1999.

LEMOS, A. Cibercultura: tecnologia e vida social na cultura contemporânea. Porto Alegre: Sulina, 2002.

LEVY, P. O que é o virtual? São Paulo: Ed. 34, 1996.

LITTO, F. M.; FORMiGA, M. M. M. Educação a distância: estado da arte. São Paulo, 2009.

MARCHESI, Á. O bem-estar dos professores: competências, emoções e valores. Porto Alegre: Artmed, 2008. 
MORAN, J. M. A educação que desejamos: novos desafios e como chegar lá. Campinas: Papirus, 2007.

NÓVOA, A. Concepções e práticas de formação contínua de professores. In:

Formação contínua de professores: realidades e perspectivas. Aveiro: Universidade de Aveiro, 1991, pp. 15-38.

Lisboa: Educa, 2009.

- Imagens do futuro professor. O regresso dos professores. Pinhais: Editora Mello, 2011.

PIMENTA, S. G.; ANASTASIOU, L. G. C. Docência no ensino superior. São Paulo: Cortez, 2002.

PIMENTA, S. G. (Org.). Saberes pedagógicos e atividade docente. São Paulo: Cortez, 1999.

PINTO, A.V. O conceito de tecnologia sob o olhar do filósofo, 2011.

SCHLEMMER, E. Projeto pedagógico comunicacional do ambiente virtual de aprendizagem - AVA 2.0. São Leopoldo: UNISINOS.

- O trabalho do professor e as novas tecnologias. Revista Textual, 2006.

SCHÖN, D. Educando o profissional reflexivo. PortoAlegre: Artes Médicas,1987.

TARDIF, M.; RAYMOND, D. Saberes, tempo do trabalho no magistério. Educação \& Sociedade, São Paulo, n. 73, 2000b.

TARDIF, M.; LESSARD, C. O trabalho docente: elementos para uma teoria da docência como profissão de interações humanas. Rio de Janeiro: Vozes, 2005.

TARDIF, M. Saberes docentes e formação profissional. 8 ed. Petrópolis: Vozes, 2007.
TARDIF, M. Saberes docentes e formação profissional. 2 ed. Petrópolis: Vozes, 2002. Saberes docentes e formação profissional. 9. ed. Petrópolis: Vozes, 2008.

Saberes profissionais dos professores e conhecimentos universitários. Disponível em: <educa.fcc.org.br/pdf/rbedu/ n13/n13a02.pdf>. Acesso em: 20 ago.2011.

VYGOTSKY,L. S. A construção do pensamento e da linguagem. São Paulo: Martins Fontes, 2001.

ZANELLA, A. V. Vygotski: contexto, contribuições à psicologia e o conceito de ZDP. Itajaí: Editora Univali, 2001.

Enviado em: 30/09/2012

Aceito em: 07/12/2012 